\title{
SUICIDE TRENDS IN SRI LANKA 1880- 2006; SOCIAL, DEMOGRAPHIC AND GEOGRAPHICAL VARIATIONS
}

\author{
N Thalagala
}

\begin{abstract}
\section{Introduction}

Sri Lanka is noted for high suicide rates for many decades. Suicide rates over time indicate an epidemic currently in the settling phase. Despite the availability of a rich source of official statistics since very early years, an in-depth analysis is yet to be carried out.
\end{abstract}

\section{Methodology}

Suicide rates as reported to the Register general and Department of Police were compiled from 1880 to 2006 . Then overall trends in suicide rates of Sri Lanka were described from 1880 to 2006 . A more detailed analysis in relation to age, sex, ethnicity, religion, and geographical region are presented from 1961 to 2006.

\section{Results}

The long standing suicide epidemic of Sri Lanka seems to have passed its peak in the mid twentieth century and presently is on declining phase. Older persons, those 60 years and above, shared the largest suicide burden through out the period. Suicides among youths were not on the rise as observed in many other countries. Male to female ratio of suicides were on the increase and lies in the range of 2 to 3. Sinhalese Buddhists had the highest suicide rate followed by the Sri Lankan Tamils who were predominantly Hindus. Moors, who follow Islam, had the lowest suicide rates. The rural agricultural districts such as Vavunia, Polonnaruwa, Anuradhapura, Kurunegala, Matale, and Kegalle reported higher rates than rest of the country.

\section{Conclusions}

The suicide epidemic of the country seems to have past its' peak around the middle of the $20^{\text {th }}$ century. Suicides among adult males have contributed to the major share of this rise in suicides. The general reduction of the suicide rates seen after mid nineteen nineties could be attributable to the policy thrusts initiated by the Presidential Taskforce on Suicide Prevention in 1997. Suicides remains to be a mental health priority even now.

\section{Keywords}

suicide trends, suicide epidemiology, Sri Lanka mental health

\section{Introduction}

Over 500,000 suicides which amount to more than 50\% of world's suicides occur in Asia. For the past 3 decades, one of the Asia's leading suicide rates are being reported from Sri Lanka [1]. The overall suicide rate of Sri Lanka is shown to be on decline since 1995. Nevertheless, not much information is available on the variations in suicide rates among different demographic, social and geographical sectors of the country [2]. Despite the availability of suicide statistics by a number of socio demographic and geographical factors through the routine information system of the Department of Police, an organized analysis is yet to be carried out. An attempt is made in this article to describe the suicide trends in relation to selected social demographic and geographical characteristics using the official statistics and there by to generate an insight in to the changing patterns of the suicide epidemiology in the country.

\section{Methodology}

The official statistics compiled by the Department of Police were analyzed to determine the time trends and the socio-demographic and geographical differentials of suicide rates in Sri Lanka. Reporting of suicides to the police is mandatory in Sri Lanka and these reports are systematically collected in a data base at the Statistical Division of the Department of Police. The coverage of the reporting is considered satisfactory [3]. This data base allows the retrieval of data related to suicide by year, age, sex, ethnicity, religion, educational status, district, motive and mode of suicide. The study analyzed this data base to determine the suicide rates of Sri Lanka over time in relation to age, sex, ethnic, religious, and geographical characteristics. Suicide statistics from the Police data base were used as numerators while census based mid year population estimates were considered as denominators [4]. The parameter specific suicide rates were presented per 100,000 persons.

Consultant Community Physician, Family Health Bureau, Ministry of Health

Correspondence: neil6338@yahoo.com 


\section{Results}

\section{Overall Suicide Trends}

Time series records on number of suicides in Sri Lanka are available since the year 1880. Analysis of number of suicide per 100000 persons indicates a gradual and consistent increase over a period of more than 10 decades, starting from 1880. During this period the national overall suicide rate has increased from 2.3 suicides per 100000 persons in 1880 to 21.2 suicides per 100000 persons in 1974. Thereafter, a dramatic increase is seen in the in overall suicide rate of the country. This rapid rising trend persisted until the year 1995, in which the country reported a highest ever overall suicide rate of 47 suicides per 100000 persons. After 1995, suicide rate has started to decline and in the year 2006 it declined to 24 suicides per 100000 persons. Figure 1 and Table 1 show the time trends of the overall suicide rates of Sri Lanka for the past 125 years.

Figure 1 Overall suicide rates in Sri Lanka since 1880 to 2006

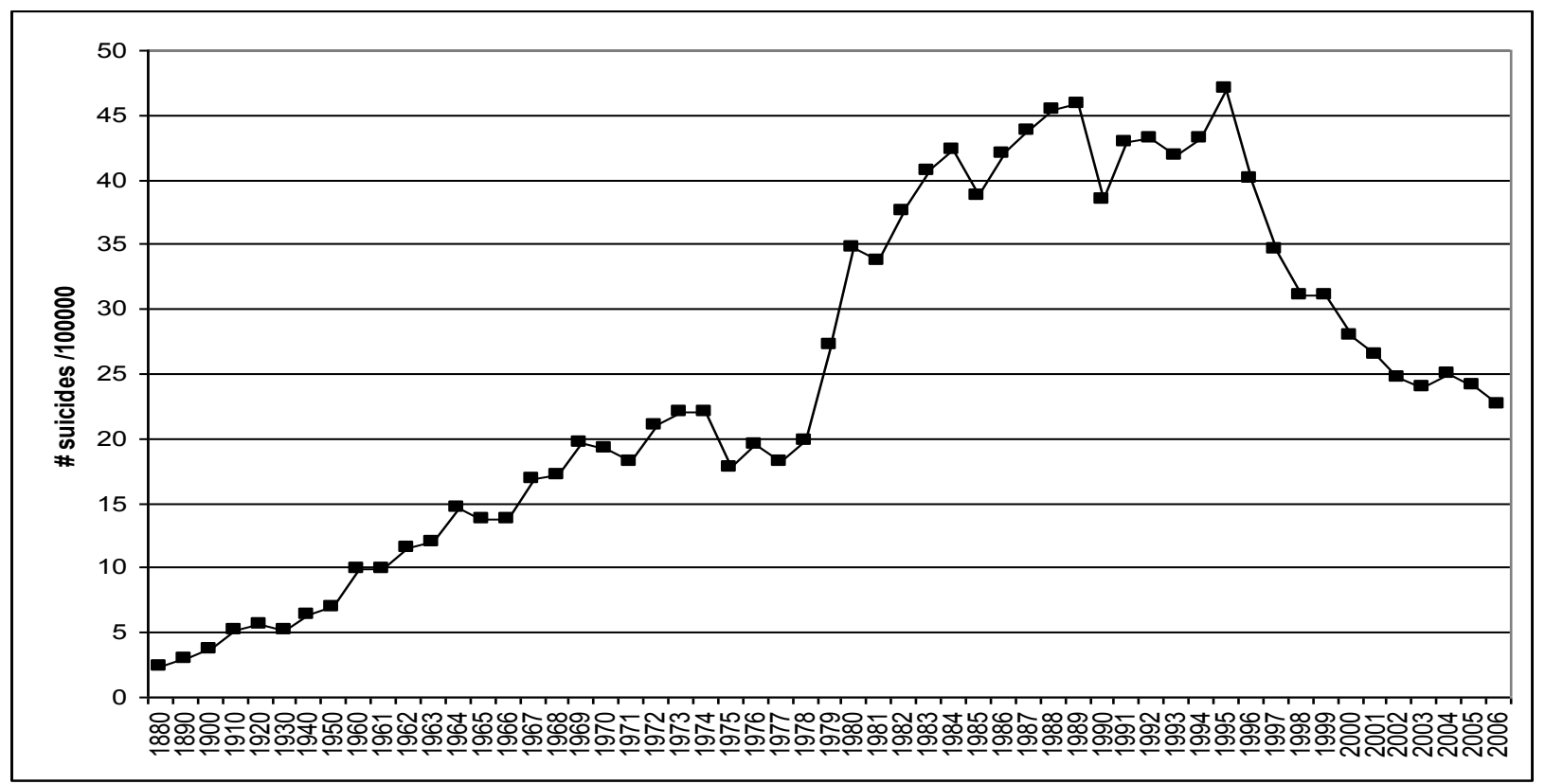

Source: Department of Police, Sri Lanka

Table 1 Suicide rates (overall, male, female) in Sri Lanka by every $10^{\text {th }}$ year since 1960 to 2005 and the male to female ratio of suicide rates

\begin{tabular}{ccccc}
\hline Year & Overall & Male & Female & Male/Female \\
\hline 1960 & 9.9 & 12.7 & 6.3 & 2.0 \\
1965 & 13.7 & 18.7 & 8.2 & 2.3 \\
1970 & 19.2 & 26.3 & 11.5 & 2.3 \\
1975 & 17.7 & 24.0 & 11.1 & 2.2 \\
1980 & 34.8 & 46.7 & 22.1 & 2.1 \\
1985 & 38.7 & 48.8 & 22.3 & 2.2 \\
1990 & 38.5 & 56.8 & 19.5 & 2.9 \\
1995 & 47.0 & 68.3 & 25.2 & 3.0 \\
\hline 2000 & 28.0 & 44.1 & 14.8 & 3.7 \\
\hline
\end{tabular}

Source: Department of Police Sri Lanka 


\section{Suicide trends by Sex}

On average both males and females have demonstrated similar patterns of rising and declining suicide trends through out the period. However, the trend of male suicide rates showed relatively higher dynamics compared to those of females. The males to female ratio of suicides remain around the value of 2 for the period extending from 1961 to 1985 . Thereafter a gradual increase in the gap between the male and female suicide rates was observed and at present the ratio remains around 4 . The increase in gap has resulted from the relatively rapid increase of male suicide rates when compared to that of females during the period from 1980 to 1995 . The highest ever male suicide rate of the country has been 68 suicides per 100000 males in the year 1995. However, the male suicide rate has declined to 36 suicides per 100000 males in the year 2006 (Figure 2).

\section{Figure 2 Suicide rates in Sri Lanka by Sex since 1961to 2006}

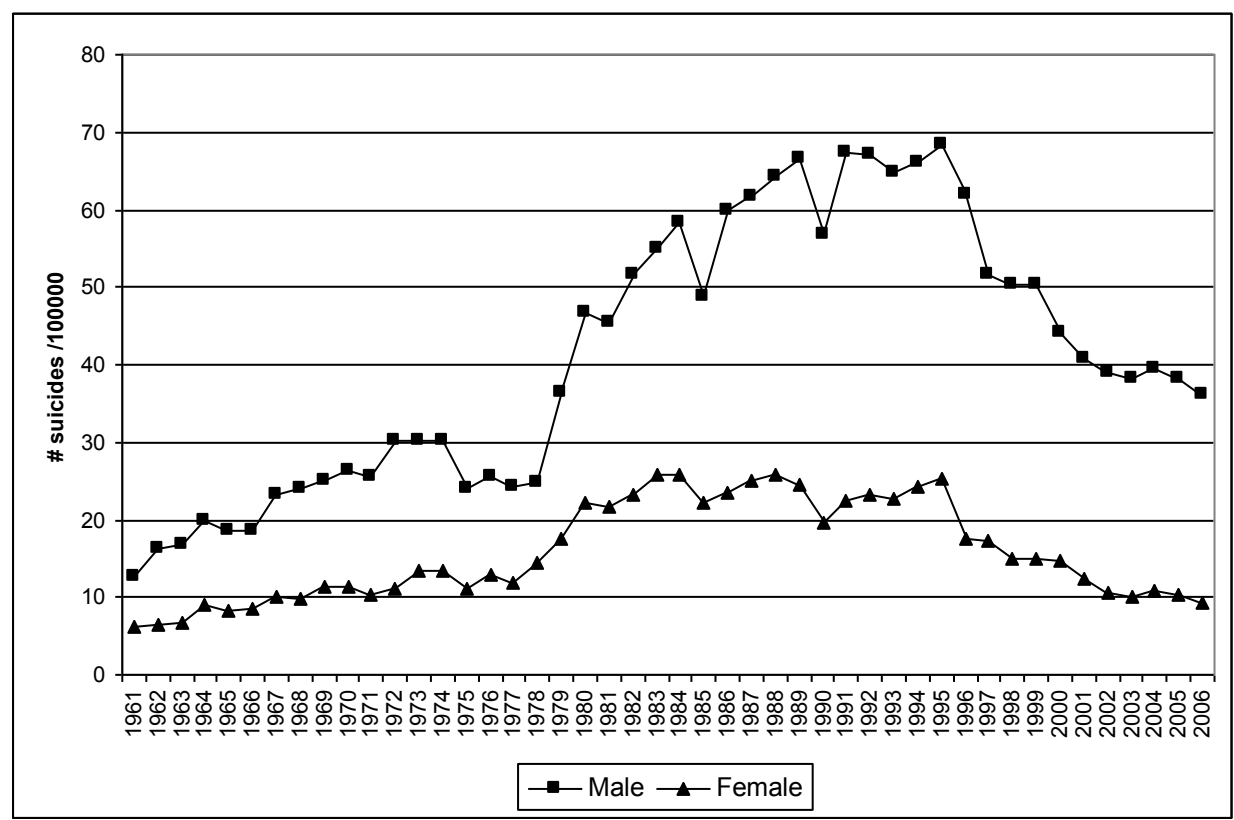

Source: Department of Police, Sri Lanka

\section{Suicide trends by age}

Age specific suicide trends seemed to be different among males and females (Figures 3 \& 4).

Figure 3 Suicide Rates in Sri Lanka by Age among Males since 1986 to 2006

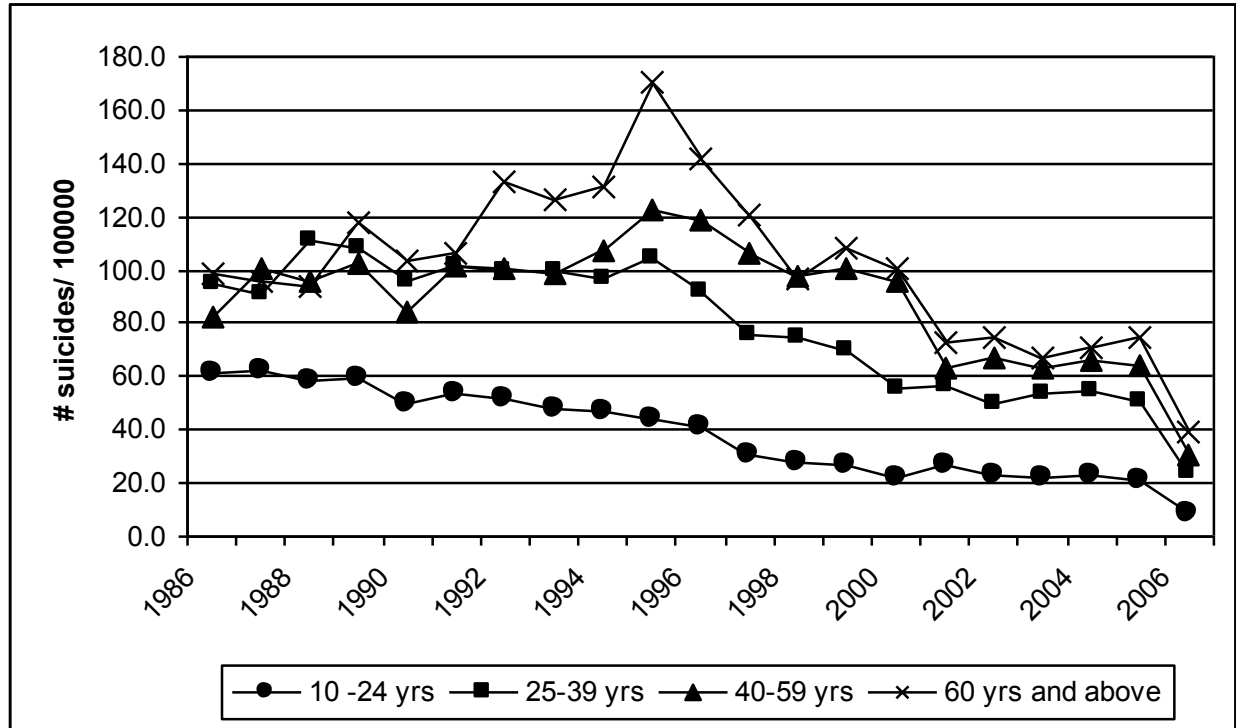

Source: Department of Police, Sri Lanka 
Suicide rates of males observed to be directly proportional to age through out the period under study. The highest suicide rates were seen in the age group 60 and above in all the years since 1986 to 2006 . The suicide rate of the age group 60 and above was at its peak in the year 1995 when it has risen to 170/ 100000 persons and it has come down to $39 /$ 100000 persons by the year 2006. The patterns of trends in suicide rates among males of different two middle age groups (25 -39 years and 40-59 years) during the period from 1996 to 1998. After the year 2000, the suicide rates of two younger age groups (10 to 24 years and 25 to 39 years) have started to overrun the suicide rates of the other older age groups. However, at present suicide rates of all four age groups seems to converge and they record the lowest ever rates for the study period. In the year 2006, the lowest suicide rate, $3 / 100000$

Figure 4 Suicide Rates in Sri Lanka by Age among Females since 1986 to 2006

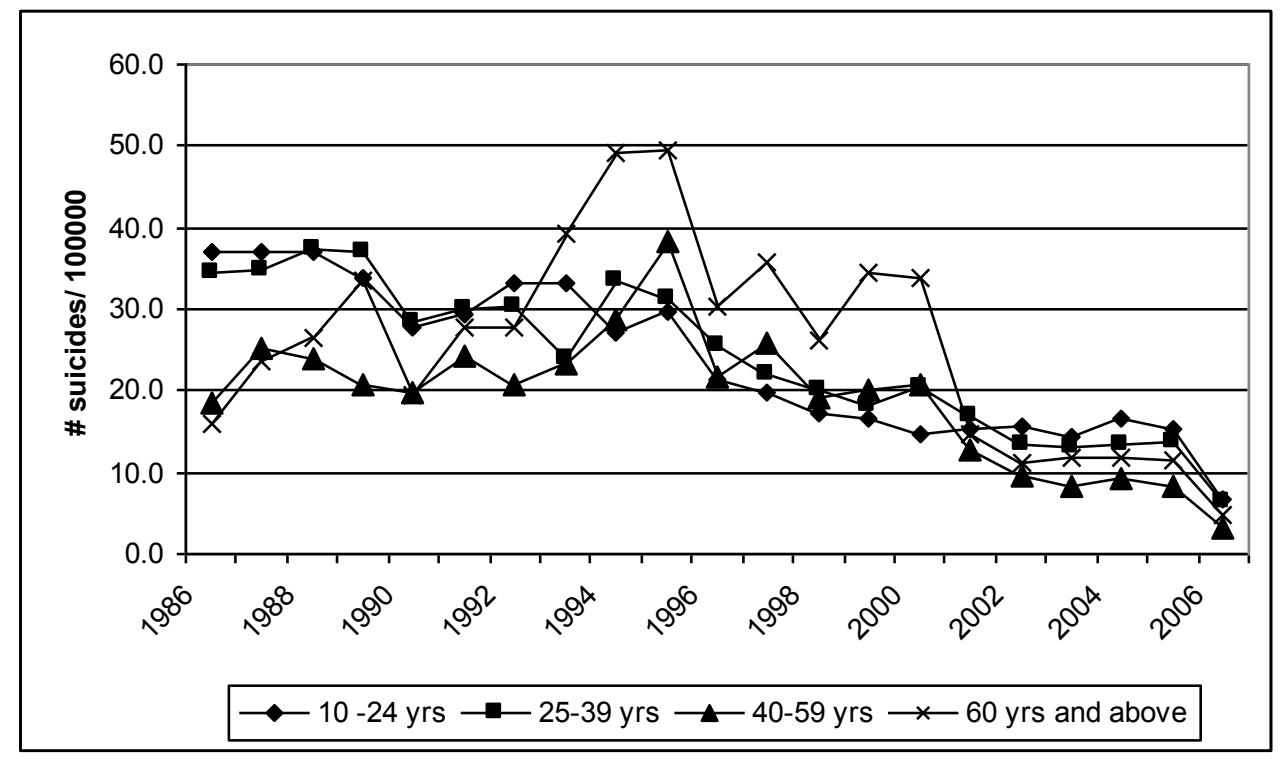

(Source: Department of Police, Sri Lanka)

ages varied. Males who were in their youth $\left(\begin{array}{lll}10 & -24\end{array}\right.$ years) have shown the lowest rates of suicide in all years since 1986 . The highest rate pertaining to this age group was reported as 62/100000 in the year 1986 and the trend has been continuously declining until the year 2006, when it was reported as 9/100000. In all other age groups there has been an escalation of suicide rates since the year 1986 to 1995 followed by a declining trend. The highest amount of rise and decline of suicide rates over time was found in the oldest age group $(60 \&$ above) while it was lowest in the 25- 39 year age group.

Pattern of suicide trends among females were distinctly different from that of males. During the initial 3 year period from $1986-1998$, the suicide rates of females were inversely proportional to the age with the lowest suicide rates were seen among females in the age group 60 years and above. During this period the highest age specific suicide rate was reported by the females in the youngest age group (10 -24 years). This pattern seemed to gradually invert over time. By the year 1995, the rates became directly proportional to age. During the period from 1995 to 2000 suicide rates pertaining to all age groups have declined. Those in higher age groups reported relatively higher suicide rates, with a slight inversion of this age: rate relationship was observed in persons was seen among the females in the 40 to 59 years age group while the highest rate for the same year, $7 / 100000$ persons was reported from females in the age group $10-24$ years. The corresponding rates for the same age categories for the year 1995 where the highest ever suicide rates were reported were 38/ 100000 and 50/ 100000 respectively.

\section{Suicide trends by Ethnicity}

A distinct ethnic difference is seen in the vulnerability to suicides amongst Sri Lankan people. The time trends in suicide rates among different ethnic groups of Sri Lanka since 1986 to 2006 is presented in Figure 5. 
Figure 5 Suicide Rates in Sri Lanka by Ethnicity since 1986 to 2006

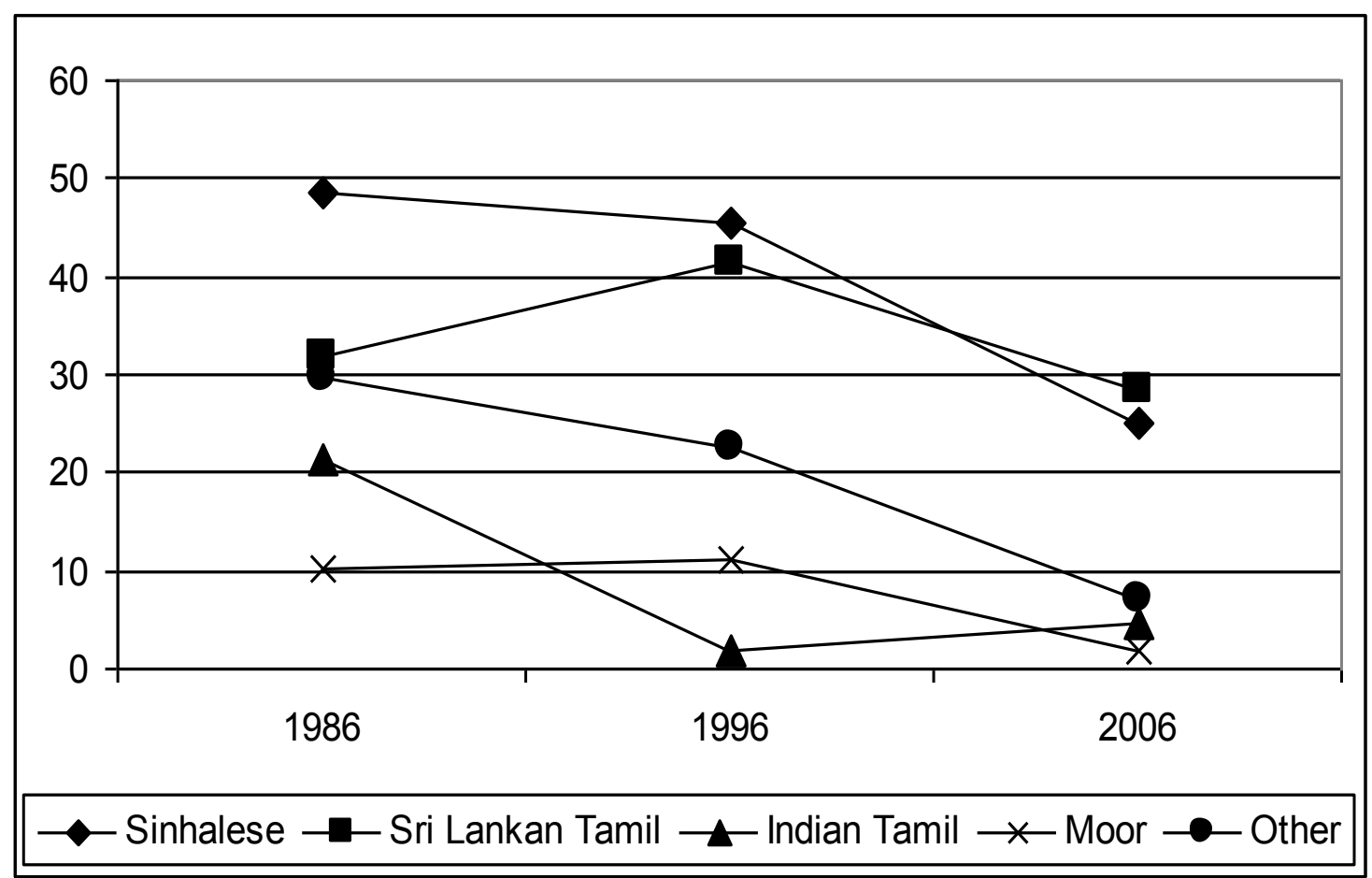

Source: Department of Police, Sri Lanka

The suicides rates were highest among the Sinhalese until around the year 2000 and afterwards, the suicide rates of Sri Lankan Tamils became the highest. The suicide rates for Sinhalese have declined from $49 /$ 100000 persons in the year 1986 to $25 / 100000$ persons in the year 2006. The rates for Sri Lankan Tamils has risen from 32/100000 persons in the year 1986 to $42 / 100000$ persons in the year 1996 thereafter declining to $28 / 100000$ persons in the year 2006. Moors recorded the lowest suicide rates except in the mid study period, around 1996, where the rates of Indian Tamils declined to the lowest level of $2 / 100000$ persons. In the year 1986 the suicide rate for Moors, 10/100000 persons which was the lowest rate for that year, has risen to $11 / 100000$ in the year 1996 and at present it remains at $2 / 100000$ persons as the lowest ethnic specific suicide rate of the country. Except among Indian Tamils the time trend of corresponding suicide rates seemed to follow the time trends of the overall national suicide rates. The minority ethnic groups that mainly comprises of Malays, Burghers and other types of Eurasians has shown a moderate suicide rate thorough out the period. The suicide rate for this group has declined from $30 / 100000$ persons in the year 1986 through $23 / 100000$ persons in 1996 to $7 / 100000$ persons in the year 2006 .

\section{Suicide trends by Religion}

Distinct religious differences in suicide vulnerability among Sri Lankan people is indicated in Figure 6 . The Buddhist has been the most vulnerable population while followers of Islam were the least vulnerable group through out the 20 year period of observation. In the year 1986 the Buddhists were having the highest suicide rate of the country which was $51 / 100000$ persons while that of Moors were $11 / 100000$ persons. Suicide rates of both these religious groups were declining since 1986 and the rates for Buddhists and Moors in the year 2006 were 26/100000 and 5/100000 persons respectively. 
Figure 6 Suicide Rates in Sri Lanka by Religion since 1986 to 2006

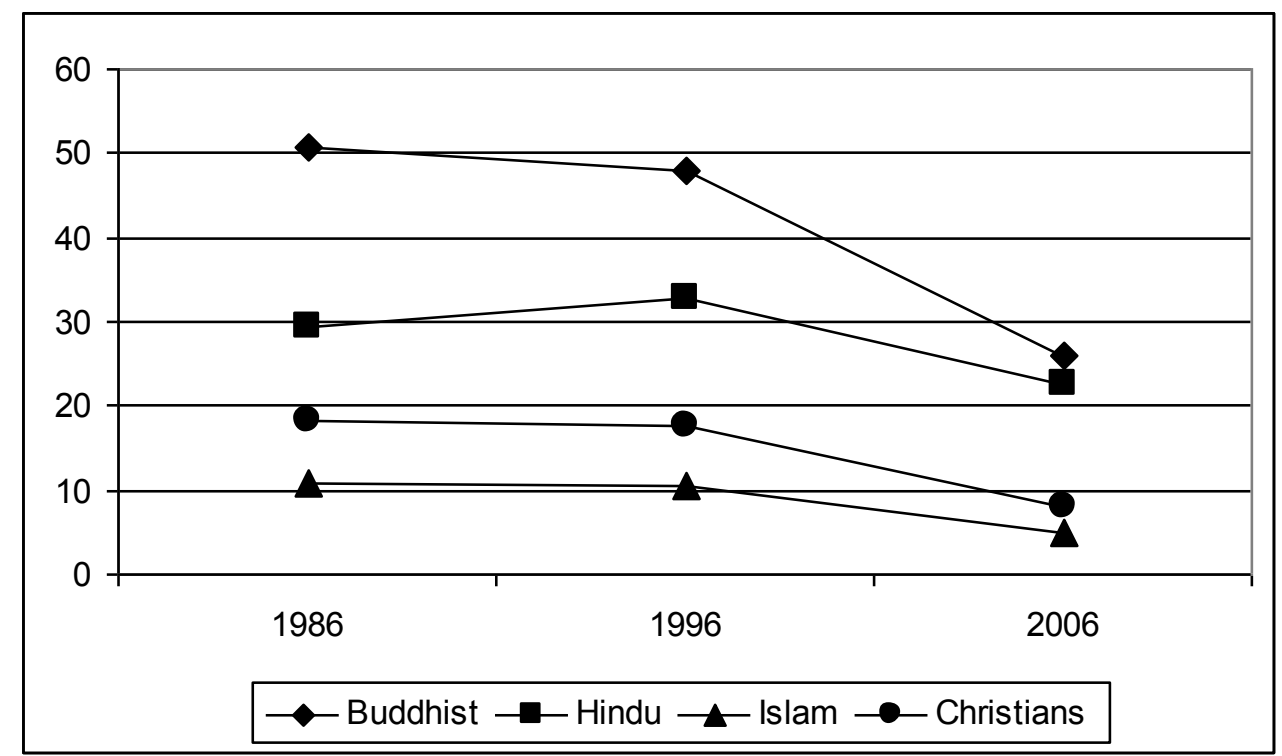

Source: Department of Police, Sri Lanka

Hindus had the second highest suicide rate of the country through out the period. A considerably higher gap between the suicide rates of Buddhists (51/100000 persons in 1986) and Hindus (29/100000 persons) in the year 1986, has seemed to have narrowed down gradually. The corresponding rates of Buddhists and Hindus in the year 1996 were 48/100000 and 33/ 10000 persons respectively. At present, in the year 2006, Buddhists' suicide rate was $26 / 100000$ persons and that of the Hindus' was 23/100000 persons. Since 1986 to 1996 the suicide rates among Christians remained more or less stable at the rate of $18 / 100000$ persons and there after the rate has declined to $8 / 100000$ persons in the year 2006.

\section{Suicide trends by geographical distribution}

A marked district variation was seen in the suicide rates (Figure 7). In analyzing the district based differences, the annual suicide rates from 1997- 2004 were averaged to reduce the inter-district random variations over time. The districts with the highest suicide rates for the period include Vaunia, Polonnaruwa, Anuradhapura, Kurunegala, Matale and Kegalle. In these districts the suicide rates ranged from 59 to $83 / 100000$ persons. The districts of Badulla,Monaragla, Rathnapura, Galle, Putthlum and Batticaloa comprised the regions with second highest suicide rates (43 to $58 / 100000$ persons). The lowest range of suicide rates, 22 to $42 / 100000$ persons was reported from Western Province (Colombo, Kaluthara and Gampaha Districts), Central Province (Kandy and Nuwara Eliya districts) and Eastern Provinces (Trincomalee and Ampara districts).

\section{Discussion}

The analysis of suicide rates indicates a significant variation of suicide vulnerability among the people from different segments of population and times. The suicide epidemic of the country seems to have past its' peak around the middle of the $20^{\text {th }}$ century. This peak was seen in all different segments of the population except among male youth, who experienced a continuously declining trend in their suicide rates.

A markedly rapid escalation is seen in suicide rate in Sri Lanka starting from early nineteen seventies that was sustained until mid nineteen nineties. Suicides among adult males have contributed to the major share of this rise in suicides. It is important to explore the possible contextual factors that would have influenced this escalation. After the independence the socio economic state of the country was gradually heading for a depression. The economic depression would have exerted its maximum impact during early nineteen seventies. The rapid population increase, high level of unemployment, increased in-migration, loosening of closely knit family and community structure could have collectively led to an increase in general societal stress which was beyond the threshold limits of some vulnerable people. The majority of suicides during this period were reported from the new agricultural settlement areas. The establishment of agricultural schemes, especially the Mahaweli Scheme, was carried out in a somewhat rapid phase. The majority of early settlers were adult males who left their families to a relatively isolated socio cultural environment in which they would have missed the rich social capital that prevailed in their original society. This kind of secluded environment is known to create an anomic status in which the suicide proneness was reported to be high [5] 


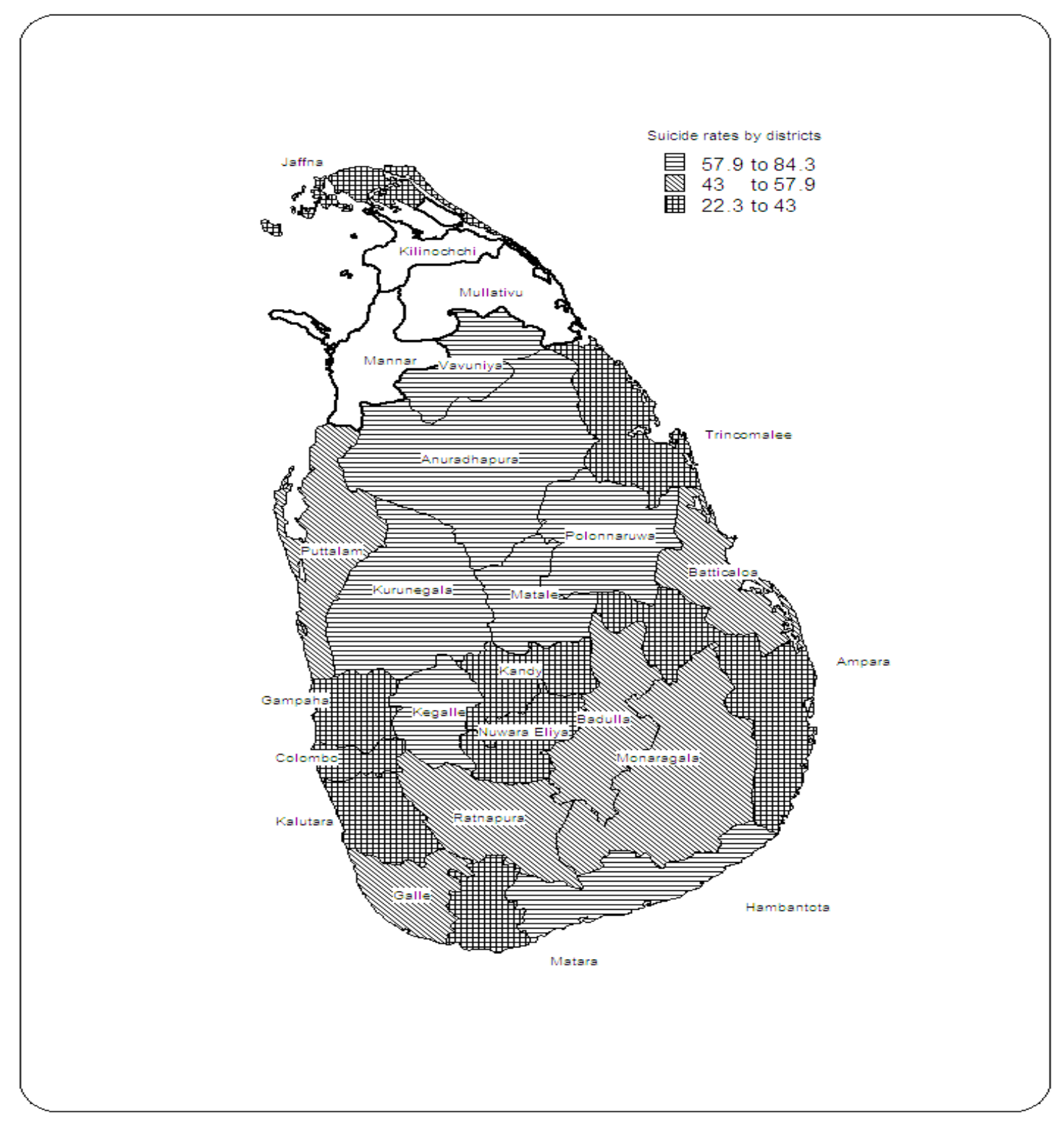

After 1996 there have been a number of strategic attempts that aimed to reduce uprising suicide rates. In the year 1997, responding to the alarms made by experts and to the outcries of general public, the Government established a Presidential Committee to study the problem and to propose an appropriate national action plan for suicide prevention. Alongside with this initiative a number of public and private organizations had embarked on suicide prevention activities. This has resulted in various interventions that included; creation of public awareness, restriction of the availability of pesticides solutions, encouraging the destruction of the plant, "Yellow Oleander", the seeds of which was commonly used as a mode of suicide, and training of health personnel, teachers and other gate keepers on suicide [2]. Unfortunately hardly any systematic evaluations were carried out to assess the impact of these efforts However, these interventions would have at least had partial contributions to the general reduction of the suicide rates seen after mid nineteen nineties.

In general suicide rates were highest among the oldest age group (60 years and above). This pattern has been maintained over time among males and females. However, in recent years, after 2001, the suicide rates of female youth (15 to 24 years) and females in 25-39 year age group have overcome those of the females who were older (40- 59 years and 60 years and above). Both these trends are important concerns to the suicide prevention activities as the present demographic structure of the country comprises a considerably higher proportion of older persons (8\%) and youths (24\%) [6]. 
Males were always having comparatively higher suicide rates than females. However, it should be noted that Sri Lankan female suicide rates were considered as the world highest female suicide rates when it was at its peak $(25 / 100000$ persons) in the year 1995 . At present the female suicide rate has come down to $10 / 100000$ persons. When the countries suicide rate was at its peak the male to female ratio of suicide rates were 2.7 where as at present time it has risen to 3.8. However, it should be noted that this increase in the gap is due to the relatively faster declining of the female suicide rates when compared to that of the males. Important observations are seen in the sex specific youth suicide rates. During the period under consideration, the suicide rates among the male youths were on the declining and those rates were always lower than the corresponding male suicide rates of older age groups. Until the year 2000, female youth were also demonstrating a declining pattern of suicide rates. However, thereafter they seem to have lost the resilience. At present highest female suicide rates are reported from the female youth. Similar kind of rising pattern of youth female suicide rates were reported in the western parts of the world in early sixties and it was attributed to the changing roles of women in those societies. The gender related societal changes resulting from the effects of globalization, and increased opportunities to women resemble the context prevailed in the West during nineteen sixties . In present setup female youth tend to have more freedom, opportunities, and unmet aspirations than their predecessors. While these factors facilitate gender equality and equity, it could also create situations of unrest and unsupportive circumstances leading to stressful lives [7].

In Sri Lanka religion and ethnicity go hand in hand. The majority of Sinhalese are Buddhist while the majority of Tamils are Hindu's. Almost all Moors follow Islam. The smaller proportion of Sinhalese and Tamils and most people from the "Others" groups who are predominantly Burghers and Malay are Christians. Sinhalese Buddhists had demonstrated the highest suicide rates through out the period of analysis, followed by Tamil Hindus. The Moors have the lowest suicide rates. The control exerted through specific religious preaching on self-harm and social interactions associated with religious activities have been attributed as the possible reasons for the variations seen in religion specific suicide rates [7-9]. Buddhists and Hindus consider committing suicide as a mortal sin. They consider one's life is predominantly one's own responsibility and individuals are considered, personally responsible for positive and negative outcomes in their lives. Finally the responsibility of self-harm is vested upon the individuals. In contrast, Islamic tradition considers suicide as a violation of the divine command that one has to accept life's events as it is. This makes an act of suicide a revolt against God. It is believed the perpetrator of such an act has to face the Gods wrath. Christianity while condemning suicide as a mortal sin and also shares beliefs related to the Gods role in life as Muslims. This fundamental difference in Islam and Christianity with Bud- dhism and Hinduism in relation to interpretation of life's events and suicide seem to have a significant role in suicidal behavior [3]. It was reported that that high rates of depression and suicide were common in cultures that induce high levels of guilt in their members as they consider themselves personally responsible for their life's experiences. On the other hand a low incidence of suicide was found in cultures with strong magico- religious beliefs and with belief systems that attribute misfortune to supernatural forces such as God that are beyond the individual's control [10]. It may be interesting to further explore the religious influence on suicide in a country with multi religious society like Sri Lanka.

District based suicide rates indicate that the leading suicide rates of the country are reported from the main agricultural districts; Polonnaruwa, Anuradhapura, Vaunia, Kurunegala, Matale and Kegalle. The most frequent explanation given to the preponderance of suicidal behavior in the agricultural regions of the country were the poverty associated life stressors among the residents in these districts and the free availability of extremely lethal pesticide solutions that people use as the most common mode of suicide [11-15]. Recently, long term chronic exposure to low doses of organophosphate pesticides was incriminated as a potential cause of depression and impulsivity and subsequently suicides [16]. The use of precautionary measures in pesticide spraying is reported as minimal in Sri Lanka due to many reasons such as lack of awareness, environmental constraints such as high humid conditions, and peer pressure. Organophosphate compounds are the most commonly used pesticides in Sri Lanka [17]. This context makes the exposure to low dose organophosphate pesticides for longer periods among farmers a common place and provided the above hypotheses is true, this may be an important factor that causes high suicide rates in the agricultural areas of the country. The districts in Western and Central Provinces had shown the lowest suicide rates. These regions represent the most socio economically developed regions of the country. The districts of Ampara and Trincomalee also belong to the region with the lowest suicide rates. Predominant presence of Muslims who had lower suicide rates would have been the reason for the low suicide risk among this region despite high prevalence of agriculture settlements. 


\section{References}

1. World Health Organization. Suicide prevention. 2007a [cited 15/03/07]; Available from: Http:// www.who.int/mental health/prevention/suicide/ suicideprevent/en/index.html.

2. Presidential Committee on Prevention of Suicide, National policy and action plan on prevention of suicide. 1997, Presidential Committee on Prevention of Suicide.

3. Dissanayake, S.A.W., Suicides and attempted suicides in Sri Lanka Ceylon Journal of Medical Science, 1974. 23: p. 10-27.

4. Department of Census and Statistics, Statistical Abstracts. 2001, Colombo: Ministry of Interior, Sri Lanka.

5. Silva, T.K. and W.D.N.R. Pushpakumara, Suicide and sexual anomie in a new settlement in Sri Lanka, in Suicide in Sri Lanka, P. De Silva, Editor. 1989, Institute of Fundamental Studies: Kandy.

6. Abeykoon, A.T.P.L., Demographic projections for Sri Lanka. Research paper seriesNo 9. 1998, Colombo: Population Division of the Ministry of Health.

7. Kerkhof, A. and A. Kunst, A European perspective on suicidal behavior, in The prevention of suicide, R. Jenkins, et al., Editors. 1994, HMSO: London. p. 22-3.

8. Stengel, E., Suicide and Attempted Suicide. 1964, Great Britain Penguine Books.

9. Ruzika, L.T., Suicides in counties and areas of ESCAP region. Asia Pacific Population Journal, 1998. 13(4): p. 55-74.

10. Marecek, J., Psychological approaches to understanding suicide, in Suicide in Sri Lanka, P. De Silva, Editor. 1989, Institute of Fundamental Studies: Kandy.

11. De Silva, H.J., et al., Suicides in Sri Lanka: points to ponder. Ceylon Medical Journal, 2000. 45: p. 17 -24 .

12. Eddleston, M., et al., Epidemiology in intentional self poisoning in rural Sri Lanka. British Journal of Psychiatry 2005. 187: p. 583-4.

13. Konradson, F., W. Van Der Hoek, and P. Peiris, Reaching for the bottle of pesticide-A cry for help. Self inflicted poisonings in Sri Lanka Social Science and Medicine, 2006. 62: p. 1710-19.

14. Van Der Hoek, W. and F. Konradsen, Risk factors for acute pesticide poisoning in Sri Lanka. Tropical Medicine and International Health 2005. 10(06): p. 589-96.

15. Thalagala, N.I., Attempted suicides, Antecedents and Consequences, in Post Graduate Institute of Medicine. 2000, University of Colombo: Colombo.

16. London, L., et al., Suicide and exposure to organophosphate insecticides: cause or effect? American Journal of Industrial Medicine, 2005. 47: p. 308-21.

17. Van Der Hoek, W., et al., Pesticide poisoning: A major health problem in Sri Lanka. Social Science and Medicine, 1998. 46(4-5): p. 495-504. 